\title{
Weighting the Positions and Skills of Volleyball Sport by Using AHP: A real life application
}

\author{
Gerçek Budak ${ }^{1}$, İmdat Kara ${ }^{2}$, Yusuf Tansel İç ${ }^{2}$ \\ ${ }^{1}$ (Department of Industrial Engineering, Adana Science and Technology University, Adana/Turkey) \\ ${ }^{2}$ (Department of Industrial Engineering, Başkent University, Ankara/Turkey)
}

\begin{abstract}
Team formation problem for sports clubs has become one of the essential challenges to be competent economically and sportively. This challenge is getting insuperable due to technological improvements in data collection, increase in the number of players and different features of the problem in different time stages. The complexity of the problem could be hurdled by using systematic methods for giving reasonable decisions. The coaches of sports clubs identify the players whether they are going to be included in the squad or in the starting line-up of the team. The skills, the positions and their importance levels should be determined for this selection process. In this paper, Analytic Hierarchy Process (AHP) is shown to be suitable for sports team formation problem to weight the skills and positions. The steps of AHP are outlined for volleyball team formation problem and a real life application of this approach for a volleyball sport club is presented. We also discuss how to use these results for decision making of a team formation.
\end{abstract}

Keywords: AHP, Team Formation, Sports, Volleyball, Coaching.

\section{Introduction}

Team formation problem for sports clubs is an assignment problem to decide which players are going to be included in the squad or selected for the line-up [1]. Decision makers of the team formation problems are managers and coaches of the sports clubs. In the last decades, sports industry has shown an extreme development economically. This has been occurred as the sponsors investments are increased, sports clubs have been entered to stock exchange markets, ticket sales and fares are increased, and for the advertisement market sports events are great opportunities to display products or services [2-4]. The relationship between financial issues and team formation problem is basically a better team for a sport club means more income [2].

Team formation problem for sports clubs is a complex decision making process as coaches consider a large number of players and their qualifications [5]. The data collectability of the number of qualifications has increased by the use of technology in sports [6-7]. The number of records of the players has become larger in size since the records of the matches are recorded and analyzed by the technical staff or statisticians of the team [7]. Another factor affecting the complexity of the problem can be identified as the number of different positions which depends on the sport branch. Each position needs different qualifications since each position has different duties during the game, and in some sport branches players could only be able to play in a particular position so that the assignment of the players to positions gets complicated [8]. With respect to these factors, it is extremely important to find an optimal or best solution for the team formation problem.

Previous researches appeared in the literature on team formation problem for sports clubs are based on different systematic approaches. Boon and Sierksma [1] suggested a linear programming model for soccer and volleyball team formation problem by using the data which are obtained by a questionnaire to the coach of the team. Trninic et al. [9] focused on a player selection procedure by using talent identification of players and by this selection, players are assigned to the positions. Tavana et al. [10] developed a two phase fuzzy inference system which utilizes the results of questionnaires to three coaches; first phase is the selection of the player and second phase is to form the team by those selected players. Ahmet et al.[11] produced a solution to cricket team selection problem with a multi-criteria decision model by using the success/trials ratios data. Dadelo et al. [12] applied TOPSIS method to players' physical measurement to find a solution for basketball team formation problem. Özceylan [13] displayed a case study on player selection for football team by using AHP priorities integrated with a linear mathematical model.

In real life, coaches are struggling with the team formation problem as there are too many points of view to the problem according to the importance levels of skills and positions. These importance levels vary on the time stage of the team formation problems. In each classified group of team formation problem, a systematically weighting procedure is necessary since a single coach's heuristic approach is insufficient and it is inevitable for the coach to make misjudgments. According to Lorains et al. [14] performance indicators should be determined and analyzed by systematic approaches. Existing researches on this subject do not tackle how to estimate the weights of the skills and positions extensively. There is only one publication on this subject for football teams where AHP is used for weighting positions and skills by using the data obtained from a computer 
game [13]. Nisel and Özdemir [15] outputs all the studies which uses AHP for sport related problems. As far as we are aware, there is no AHP application on volleyball sports with real life data. Thus, to establish a systematic way for estimation of the weights of the positions and skills for the volleyball sport is the main motivation of this research. This paper proposes a real life based AHP approach as a weighting procedure of the positions and skills for team formation problem for sports clubs and outputs the usage of these weights for player selection to the positions. This is the main contribution of this paper.The main uncontrollable variables, i.e. parameters or technical coefficients of all types of decisions for team formation problem, there is a need to find out the effects of the positions and skills for the result of the game. Those aspects of the team formation problem are discussed in Section II. In the third section, we propose AHP as a scientific tool in order to estimate the effects of positions and skills and we discuss how to use those weights for a team formation problem. We summarize the results of our approach for a real life volleyball application in this section as well. The conclusions are outlined in the last section.

\section{Positions and Skills of a Sport}

In general, a team is a group of players who have the same goals to achieve by contributing on different responsibilities [16]. These responsibilities are execution of different skills during the game. Those executions of skills lead to a separation of positions which are the labels of each player on the field having the same duties in-play of the game [17]. In other words, the players who assigned to particular positions have specified roles which affect the result of the game directly or indirectly. In the great scheme of things, the level of performance made by players determines the result of the game since either a player's performance determine the result or it effects the other positional players. Players in each position needs to satisfy a skill level to participate according to the duty [18]. The appraising question for the team coach is: Which position and skills are relatively important to other skills and positions? Another question to be answered is: what are the importance levels of each of them? The coaches evaluate skills of the players to assign each player to a position. They generally make this decision according to past experience and knowledge of each player [5]. However, this evaluation might be misleading unless the coach can consider every player and their performance levels. This framework suggests that each skill has to have an importance level for winning the game and each position has different importance levels for a particular skill so that the coach is going to be able to identify the quantitative benchmark of each player. To sum up, coaches should weight the skills and weight the positions considering the importance of them before the team formation for winning the upcoming game. Therefore, setting these importance levels is necessary for implementing a decision making tool [10-12].

Team formation problem for sports clubs is a hierarchically structured problem with respect to effect of the skills and positions as shown below in Fig. 1 which is a general demonstration for team formation problem. Team formation for Team A requires " $n$ " number of skills to be considered. Each skill has been executed by different number of positions. The first skill is provided by " $m$ " number of skills as shown in the Fig. 1. Thus for each sport branch this hierarchical structure varies in terms of " $\mathrm{n}$ " and "m".

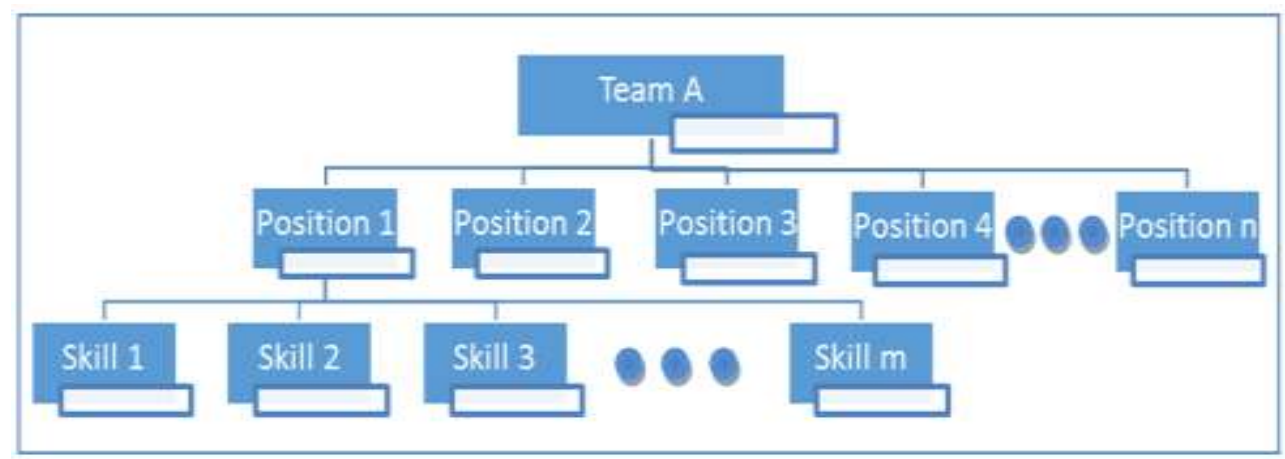

Figure 1: General Hierarchical Structure for Team Formation Problems.

According to Toyoda [19] volleyball sport has seven positional players which are middle blocker1 (MB1), middle blocker2 (MB2), setter (S), opposite player (OP), side player1 (SP1), side player2 (SP2) and libero (L) and five main skills which are blocking, attacking, serving, reception and passing. Each skill is being carried out by different positional players in different proportions. For volleyball teams Fig. 2 given below shows the hierarchy of the volleyball team formation problem. 


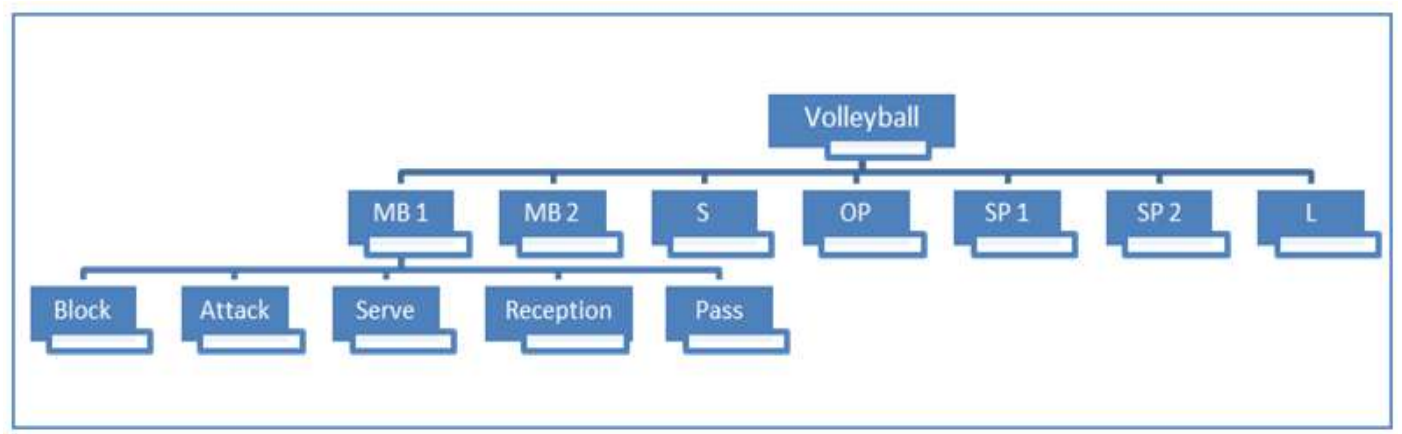

Figure 2: Hierarchy of the volleyball team formation problem.

In the following section, we propose to use AHP approach for estimation of the weights of the positions and skills that may be used during the decision making process of team formation.

\section{Analytical Hierarchy Process Approach for Weighting the Positions and Skills for Volleyball Sport}

Analytical Hierarchy Process (AHP) is one of the Multi-Criteria Decision Making (MCDM) methods to weight each factors by using pair-wise comparisons [20]. In the related literature, there are many different multi criteria decision problems and applications where AHP is used for a weighting methodology. AHP is used in financial engineering problems [21], performance measurement problems [22], supply chain management problem [23] and other areas. In AHP, decision makers of hierarchical problems are being asked to compare the factors (criteria, objectives, alternatives etc.) pair-wisely which are at same level of hierarchy and the answers of each comparison evaluated according to the scale of importance level which is shown in Table 1. If the number of criteria is " $k$ ", in a matrix format which is " $\mathrm{k} \times \mathrm{k}$ ", the comparison element $\mathrm{i}$ to $\mathrm{j}$ is going to be $\mathrm{A}_{\mathrm{ij}}$ and $\mathrm{A}_{\mathrm{ji}}$ is going to have the value of $1 / \mathrm{A}_{\mathrm{ij}}$ [20-22].

Table 1: Saaty's 1-9 Scale for Pair-wise Comparisons (Saaty, 2012)

\begin{tabular}{|l|l|}
\hline Value of importance rate & Definition and Explanation \\
\hline 1 & Important equally: Two criteria have equal contributions \\
\hline 3 & Important moderately: One criterion important than the other weakly \\
\hline 5 & Important strongly: One criterion important than the other strongly \\
\hline 7 & Important very strongly: One criterion important than the other very strongly \\
\hline 9 & Important extremely: Highest possible importance over the other criterion \\
\hline $2,4,6,8$ & $\begin{array}{l}\text { Intermediate values of the rate: Compromising between the two levels of importance } \\
\text { definitions. }\end{array}$ \\
\hline Reciprocals of above & $\begin{array}{l}\text { If criterion } \mathrm{i} \text { has one of the above numbers assigned to it when compared with criterion } \mathrm{j} ; \\
\text { then criterion } \mathrm{j} \text { has the reciprocal value when compared with criterion } \mathrm{i} .\end{array}$ \\
\hline
\end{tabular}

AHP has been widely used in different decision making problems [22]. In sports industry AHP is only used for evaluating just player performances according to skill and ability of the football players by Sipahi and Or [24] and Özceylan [13]. Chen et al. [25] used AHP method for weighting the criteria for starting-pitcher selection and applied TOPSIS method for ranking the players. For other studies see Nisel and Özdemir [15].

As described in section II, team formation problem has a hierarchical aspect that is the necessary condition for AHP application. In addition to this, we need relative importance of the positions and skills where the AHP is a widely used scientific tool. As the coaches set the importance levels by personal judgements, these personal setting of the levels must be controlled by a method to measure the consistency. AHP methodology has a consistency checking methodology which overcomes this situation. Besides these reasons, AHP is a deductive approach for different complexity levels which enables the decision makers to adopt their problem to different types easily. AHP is a flexible model as re-judging the comparisons can be made easily if it is necessary. Finally, AHP gives a scale for measurement for the qualitative judgements since for sport industry statistical data getting more important, there is an obvious need for quantifying those qualitative judgements [20]. Consequently, AHP is a scientific tool for weighting skills and positions for sports clubs. Such applications are conducted on football and basketball sports but there is no application on volleyball sport.

\section{1) Procedure of AHP for Volleyball Sport}

This sub-section demonstrates the work flow of an AHP for volleyball sport. The steps of AHP are clearly shown in Fig. 3 which is presented below as a process chart. 


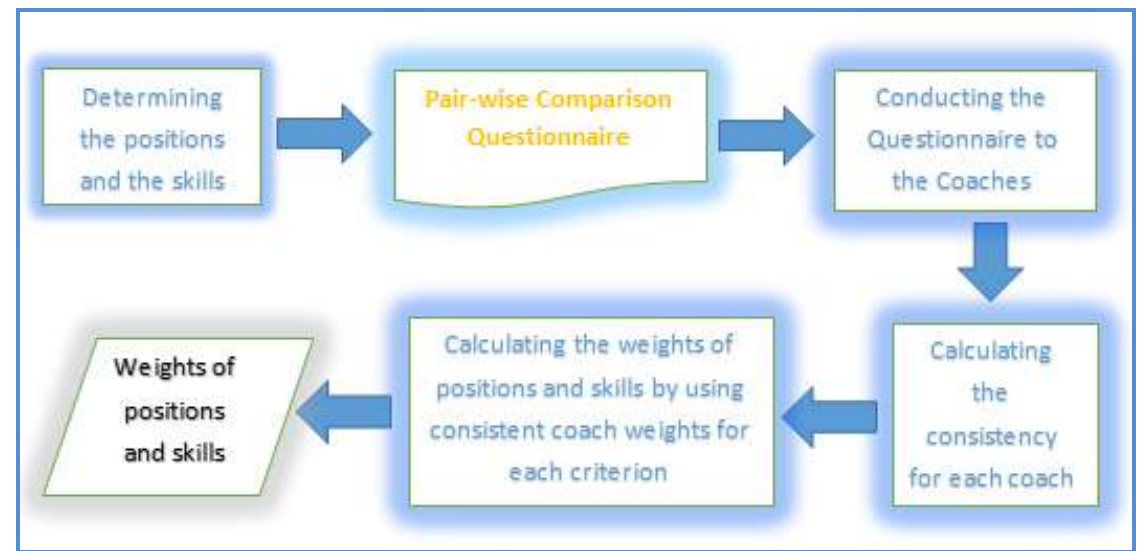

Figure 3: Flow chart of Analytical Hierarchy Process for Volleyball Sport

As shown in Fig. 3, the first step is to determine the volleyball sport's positions and skills. By use of this determination, a questionnaire must be prepared which includes pairwise comparison questions of positions and skill for each position. The next step that should be followed is to conduct the prepared questionnaire to the professional volleyball coaches one at a time. After completing all of the coaches, by using the consistency calculation of AHP each coach's pairwise judgements should be evaluated. The consistent weights for each criterion are processed with geometric average and therefore the weights of each position and skill are obtained.

\section{2) A Real Life Volleyball Application}

The flow chart which displayed on Fig. 3 is followed appropriately. The first step in Fig. 3 is determining the positions and skills for volleyball sport. As discussed in Section II, there are 7 positions and 5 skills that shape the team and the match play of the volleyball sport. After the determination of positions and skills, the questionnaire for pair-wise comparisons of them must be constructed. This questionnaire has 6 subsections which are the pairwise comparisons of positions and pairwise comparisons of skills for each position. The middle blocker positions are taken as 1 position since it is the same position and 2 players are assigned. This situation is also valid for the side player positions. An example question in the questionnaire is shown in Appendix A. This question requires a selection between setter and libero position and identification of the strength of their relation unless these two positions are equally important.

Pairwise comparisons are applied with the formed questionnaire to 20 professional volleyball team coaches which have a coaching license given from Turkish Volleyball Federation. The participants of the questionnaires are 12 men's and 8 women's volleyball coaches. The results of pairwise comparisons for each coach are presented in Appendix B.The results shown in Appendix B is obtained by questionnaires which are conducted by one by one meeting with each coach. Each column represents the weights of positions and skills of one coach which are derived and normalized from the questionnaire results. Consistency index for the pair-wise comparisons for each coach are calculated. Consistent judgments are processed with geometric average to obtain the weights for each criterion.

As there are two groups (men's and women's), there is a need to question whether those two groups' pair-wise comparisons have the same distribution or not. In this point a non-parametric Mann Whitney U test is applied with the following hypotheses [26].

$\mathrm{H}_{0}$ : There is no significant difference between men's and women's volleyball coaches' weights.

$\mathrm{H}_{1}$ : There is a significant difference between men's and women's volleyball coaches' weights.

The test is applied on Minitab 14.0 and p values are given below in Table 2. As these p values are greater than 0.05 , there is no evidence to reject the $\mathrm{H}_{0}$ hypothesis.

Table 2: p values for Mann Whitney U Test.

\begin{tabular}{|l|l|l|l|l|l|}
\hline Parameter/Skills & Serve & Reception & Block & Attack & Pass \\
\hline p (Asymp. Sig. 2-tailed) & 0.953 & 0.639 & 0.953 & 0.598 & 0.159 \\
\hline
\end{tabular}

According to the p values shown in Table 2, men's and women's coaches can be both used at the same time to obtain the weights of positions and skills as there is no significant difference between them. So that, we may combine the data obtained from men's and women's volleyball team coaches. The geometric mean of the consistent judgments of both men's and women's coaches are calculated and given under GA column of the Appendix B. Then by normalizing the results we obtained the corresponding weights under $\mathrm{W}$ column of Appendix B. The importance levels of the positions are given in Table 3 and importance levels of skills are given in Table 4. 
Table 3: Importance levels of positions

\begin{tabular}{|l|l|l|l|l|l|l|l|l|}
\hline Positions & S & L & MB1 & MB2 & SP1 & SP2 & O & Total \\
\hline Weights & 0.26 & 0.07 & 0.12 & 0.12 & 0.13 & 0.13 & 0.18 & 1.00 \\
\hline
\end{tabular}

The results of the twenty coaches output that the most important position for volleyball sport is setter. This is an expected situation as the setter is the playmaker of the volleyball sport. According to the Table 3 , the player who assigned to the setter position has a higher effect on the match score compared to the other positions. It can be referred that the decision maker of the team formation problem must concern the assignment of a player to setter position more than others. The descending order of the importance levels are opposite position, side player positions, middle blocker positions and libero position.

Table 4: Importance levels of skills for each position

\begin{tabular}{|l|l|l|l|l|l|l|l|}
\hline Position/Skill & S & L & MB1 & MB2 & SP1 & SP2 & O \\
\hline Serve & 0.21 & 0.00 & 0.27 & 0.27 & 0.21 & 0.21 & 0.27 \\
\hline Reception & 0.00 & 1.00 & 0.00 & 0.00 & 0.44 & 0.44 & 0.00 \\
\hline Block & 0.16 & 0.00 & 0.54 & 0.54 & 0.12 & 0.12 & 0.22 \\
\hline Attack & 0.00 & 0.00 & 0.18 & 0.18 & 0.22 & 0.22 & 0.51 \\
\hline Pass & 0.63 & 0.00 & 0.00 & 0.00 & 0.00 & 0.00 & 0.00 \\
\hline Total & 1.00 & 1.00 & 1.00 & 1.00 & 1.00 & 1.00 & 1.00 \\
\hline
\end{tabular}

The results shown in Table 4 harmonize with Toyoda [19]'s expectations such as the most important skill for setter is pass, for libero and side players is reception, for middle blockers is blocking and for opposite player is attacking. Team coach should refer to the importance levels of the skills for each position's player assignment.Importance levels of positions in matrix form is dimensioned as $1 \mathrm{x} 7$ and called as $\mathrm{P}$ matrix. Importance levels of skills for each position in matrix form is dimensioned as $7 \times 5$ and called as PS matrix. By using Table 3 and Table 4 as matrices, the matrix multiplication of them gives the importance levels of skills. Therefore, the importance level of skills in matrix form is dimensioned $1 \times 5$ and called as $\mathrm{S}$. The mathematical transection can be shown as $\mathrm{S}=\mathrm{P}_{[1 \times 7]} \times \mathrm{PS}_{[7 \times 5]}$. This multiplication is applied and the results are given below in Table 5.

Table 5: Weights of Skills

\begin{tabular}{|l|l|l|l|l|l|}
\hline Skills & Serve & Reception & Block & Attack & Pass \\
\hline Weights & 0.220 & 0.184 & 0.240 & 0.192 & 0.164 \\
\hline
\end{tabular}

As shown in Table 5, the most important skill is blocking. The multiplication results can be interpreted as a team with a great blocking and serving skills approximately overwhelms the half of the game to win the match. The skills can be lined up as blocking, serving, attacking, receiving and passing in descending order.

\section{3) How to Use the AHP Results?}

The fundamental question of the team formation problem is to answer which players are going to be included in the team. Obviously, there is a need of benchmarking the players according to their skill levels. As AHP supplies weights of positions and skills for team formation problem by the shown steps at section III.1, the coaches need a decision making methodology to use the obtained weights. The selection of the players may be done by ranking the players according their skill levels. To establish this, the coaches should forecast the players' future performance dependent on each skill or position to operate a decision making methodology. This forecast can be made based on the past performances, anthropometric measurements, assessments of the coach and etc. $[10,12]$. By this estimation of " $\mathrm{m}$ " number of skills for " $\mathrm{k}$ " number of players, $\mathrm{m} \times \mathrm{k}$ sized matrix can be formed. By using the weights of each skill which $\mathrm{k} \times 1$ sized in matrix form, the matrix multiplication is going to give the effect of each player to the result of the game. Then, sorting these players in descending order and assign the players from the highest rank according to the needed position will supply the formed team. Applying this method reduces the complexity of the problem and gives systematical formed team.

More general sense, those weights obtained at the end of the AHP approach may be used as main parameters of decision models developed for team formation problems.

\section{Conclusion}

The common requirement for finding a solution to the team formation problem is identifying the importance levels of skills and positions. This research simplifies the player selection process for the volleyball team coaches as the AHP results supply the weights to benchmark the players. These weights make it easier to the coach for benchmarking the players' performances by applying a decision making tool.Team formation problem is structured hierarchically and AHP method is applied for scaling because of its advantages that this technique brings such as easiness of inference, deduction, consistency checking and re-judgement. 
To sum up, this research presents AHP method for the team formation problem and application of AHP is executed to volleyball team's weighting of the skills and positions. The results of AHP can be used as an input to the decision models for team formation problem. Such approaches as a further research are under construction.

\section{References}

[1] B.H. Boon, and G. Sierksma, Team formation: Matching quality supply and quality demand, European Journal of Operational Research, 148(2), 2003, 277-292.

[2] S. Rosner, and K.L. Shropshire, The Business of Sports (Jones \& Bartlett Learning: 2004)

[3] C. Gratton, S. Shibli, and R. Coleman, Sport and economic regeneration in cities, Urban studies, 42(5-6), 2005, 985-999.

[4] C.A. Caro, College football success: The relationship between recruiting and winning, International Journal of Sports Science \& Coaching, 7(1), 2012, 139-152.

[5] C. Cushion, Modelling the complexity of the coaching process, International Journal of Sports Science \& Coaching, 2(4), 2007, 395-401.

[6] D.G. Liebermann, L. Katz, M.D. Hughes, R.M. Bartlett, J. McClements, and I.M. Franks, Advances in the application of information technology to sport performance, Journal of sports sciences, 20(10), 2002, 755-769.

[7] B.D. Wilson, Development in video technology for coaching, Sports Technology, 1(1), 2008, 34-40.

[8] V.D. Salvo, R. Baron, H. Tschan, M.F.J. Calderon, N. Bachl, and F. Pigozzi, Performance Characteristics According to Playing Position in Elite Soccer, International Journal of Sports Medicine, 28, 2007, 222 - 227.

[9] S. Trninić, V. Papić, V. Trninić, and D. Vukičević, Player selection procedures in team sports games, Acta Kinesiologica, 2(1), 2008, 24-28.

[10] M. Tavana, F. Azizi, F. Azizi, and M. Behzadian, A fuzzy inference system with application to player selection and team formation in multi-player sports, Sport Management Review, 16(1), 2013, 97-110.

[11] F. Ahmed, K. Deb, and A. Jindal, Multi-objective optimization and decision making approaches to cricket team selection, Applied Soft Computing, 13(1), 2013, 402-414.

[12] S. Dadelo, Z. Turskis, E.K. Zavadskas, and R. Dadeliene, Multi-criteria assessment and ranking system of sport team formation based on objective-measured values of criteria set, Expert Systems with Applications, 41(14), 2014, 6106-6113.

[13] E. Ozceylan, A mathematical model using AHP priorities for soccer player selection: a case study, South African Journal of Industrial Engineering, 27(2), 2016, 190-205.

[14] M. Lorains, K. Ball, and C. MacMahon, Performance analysis for decision making in team sports, International Journal of Performance Analysis in Sport, 13(1), 2013, 110-119.

[15] S. Nisel, and M. Özdemir, Analytic Hierarchy Process \& Analytic Network Process in Sport: A Comprehensive Literature Review, International Journal of Analytic Hierarchy Process, 3, 2016, 405-429.

[16] J.R. Katzenbach, and D.K. Smith, The wisdom of team (Harvard Business School Press, Boston: 1993).

[17] P.T. Nikolaidis, Physical fitness in female soccer players by player position: a focus on anaerobic power, Human Movement, 15(2), 2014, 74-79.

[18] C. Sullivan, J.C. Bilsborough, M. Cianciosi, J. Hocking, J. Cordy and A.J. Coutts, Match score affects activity profile and skill performance in professional Australian Football players, Journal of Science and Medicine in Sport, 17(3), $2014,326-331$.

[19] H. Toyoda, Coaches Manual I: ChapterV -Volleyball for beginners (Fédération Internationale de Volleyball:2011).

[20] T.L. Saaty, Decision Making for leaders: The analytic hierarchy process for decisions in a complex world (RWS Publications, Pittsburgh: 2012).

[21] M. Yurdakul, and Y.T. İç, AHP approach in the credit evaluation of the manufacturing firms in Turkey, International journal of production economics, 88(3), 2004, 269-289.

[22] E.W. Cheng, and H. Li, Analytic hierarchy process: an approach to determine measures for business performance, Measuring Business Excellence, 5(3), 2001, 30-37.

[23] C.L. Tramarico, V.A.P. Salomon, and F.A.S. Marins, Analytic hierarchy process and supply chain management: A bibliometric study, Procedia Computer Science, 55, 2015, 441-450.

[24] S. Sipahi, and E. Or, Evaluating the Success in Football According to Ability and Skills Using Analytic Hierarchy Process (AHP), Istanbul University Business Management Faculty Business Economy Institution Journal, 16(50), 2005, 53-65 [In Turkish].

[25] C.C. Chen, Y.T. Lee, and C.M. Tsai, Professional baseball team starting pitcher selection using AHP and TOPSIS methods, International Journal of Performance Analysis in Sport, 14(2), 2014, 545-563.

[26] H.B. Mann, and D.R. Whitney, On a test of whether one of two random variables is stochastically larger than the other, The annals of mathematical statistics, 1947, 50-60.

Appendix A: Example Question from the Questionnaire

Section 1

Q1) Choose the most important position between setter and libero.
a) Setter
b)Libero
c)Equally Important

Identify the importance level between them unless those positions are important equally.

i) Important moderately ii) Important strongly

iii) Important very strongly

iv) Important extremely 
Weighting the Positions and Skills of Volleyball Sport by Using AHP: A real life application

Appendix B: AHP Results for Each Coach and Geometric Averages

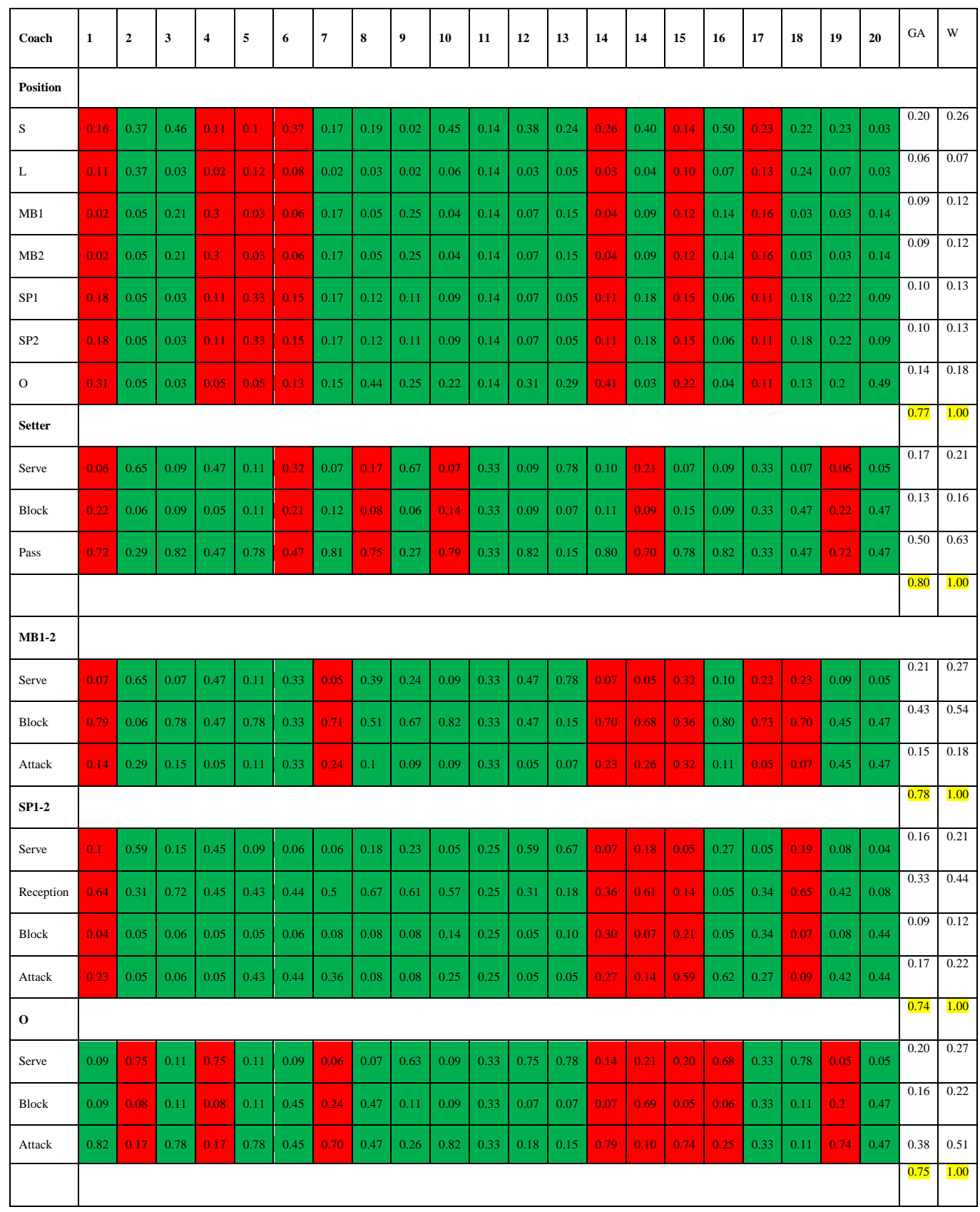

Note: The segments labelled with red color shows inconsistent comparisons and the green color shows consistent comparisons. GA and $\mathrm{W}$ are abbreviations of geometric average and weights. 